\title{
ANESTHETIC MANAGEMENT DURING OPEN SURGERY OF THORACOABDOMINAL ANEURYSM REPAIR WITH EXTRACORPOREAL MEMBRANE OXYGENATION. OUR EXPERIENCE IN 13 CASES
}

Bueno L. ', Pérez P. ', Fossati S. ', Beltrao R. ', Serrano J. ${ }^{2}$, Aguilar C'.

Department of Anaesthesiology and Critical Care. ${ }^{1}$ Department of Vascular Surgery. ${ }^{2}$ Hospital Clínico San Carlos. Madrid.

\section{BACKGROUND:}

Open repair of thoracoabdominal aortic aneurysms (ORTAAA) is one of the most demanding and challenging interventions due to the compromise of the visceral and spinal cord blood flow. Further classical approaches (range from "clamp and sew" technique to left atrial femoral bypass), extracorporeal membrane oxygenation (ECMO) could offer advantages: easier implantation technique, less surgical exposure, control on patient's temperature or improved oxygenation and tolerance during one-lung ventilation.

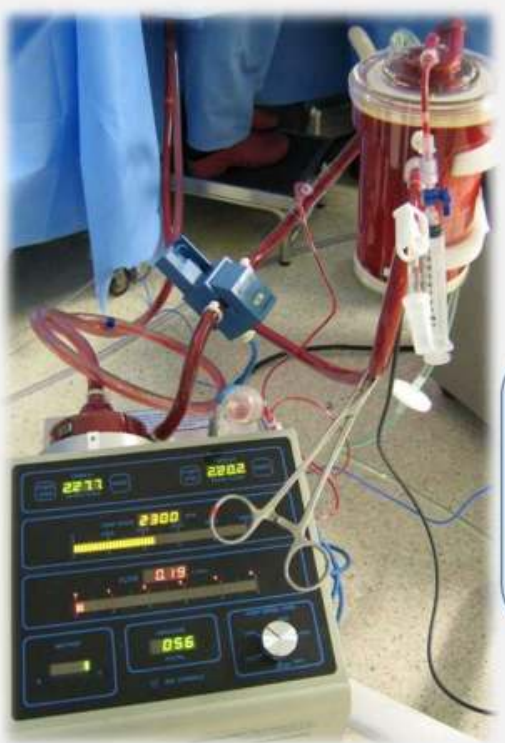

\section{GOAL OF THE STUDY:}

The aim of this study is to describe the anaesthetic management of 13 patients undergoing elective ORTAAA using ECMO, as well as to identify a potential decrease in perioperative complications and its predictors.

\section{MATERIAL AND METHODS:}

A series of 13 patients, collected from 2015 to 2017 submitted to ORTAAA (usually Crawford type 3) throught ECMO. We analyze the predictors of paraplegia and acute renal failure (ARF) the Pearson Chi-square test.

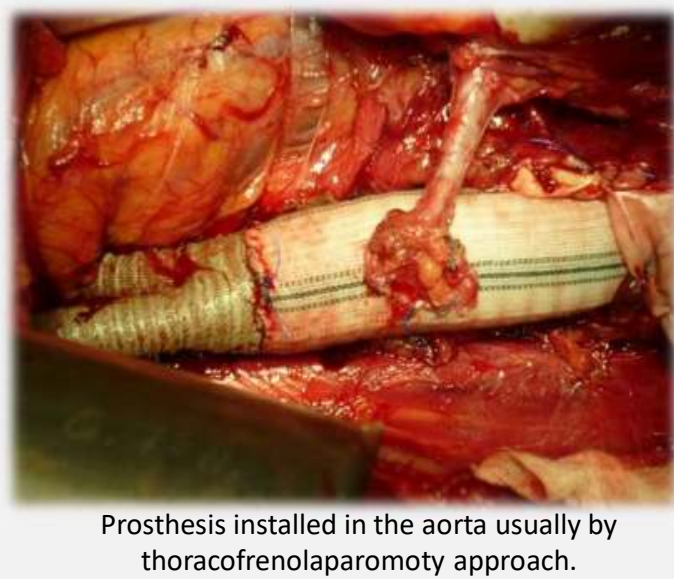

There were performed through balanced general anaesthesia with univent bronquial blocker, invasive monitoring, pulmonary artery catheter (Swan-Ganz), transoesophageal ecocardiography, epidural catheter and cerebrospinal fluid drainage system.

\section{RESULTS AND DISCUSSION:}

We got ischemia times below 30 minutes in 6 patients (46\%), between 30-60 minutes in other 6 patients (46\%) and above 60 minutes in 1 patient $(8 \%)$.

$\square$ Cross-clamp times greater than 60 minutes make 1,2 times $(O R=8,33)$ more likely to suffer renal failure.

- $100 \%$ of patients with a time greater than 60 minutes had paraplegia. And $16,7 \%$ with time less $\tan 30$ minutes.

Although the results were not significant $(p>0.04)$.

\begin{tabular}{|c|c|c|}
\hline $\begin{array}{l}\text { PERIOPERATIVE } \\
\text { COMPLICATIONS }\end{array}$ & $\begin{array}{l}\text { NUMBER OF } \\
\text { PATIENTS (\%) }\end{array}$ & \\
\hline Neurological & $2(15.3 \%)$ & Paraplegia \\
\hline Cardiovascular & $3(23 \%)$ & Atrial fibrillation \\
\hline Respiratory & $3(23 \%)$ & $\begin{array}{l}\text { Prolongued mechanical } \\
\text { ventilation ( } 2 \text { tracheostomy) }\end{array}$ \\
\hline Renal & $\begin{array}{l}11(84.6 \%)<24 \text { hs. } \\
2(15.3 \%)>48 \text { hs. }\end{array}$ & $\begin{array}{l}\text { Acute renal failure } \\
\text { Renal replacement therapy }\end{array}$ \\
\hline 30-day Mortality & $2(15.3 \%)$ & $\begin{array}{l}\text { Multiorganic failure and massive } \\
\text { hemorrhage }\end{array}$ \\
\hline
\end{tabular}

VISCERAL BRANCHES CROSS-CLAMP TIMES: (Ischemia times)
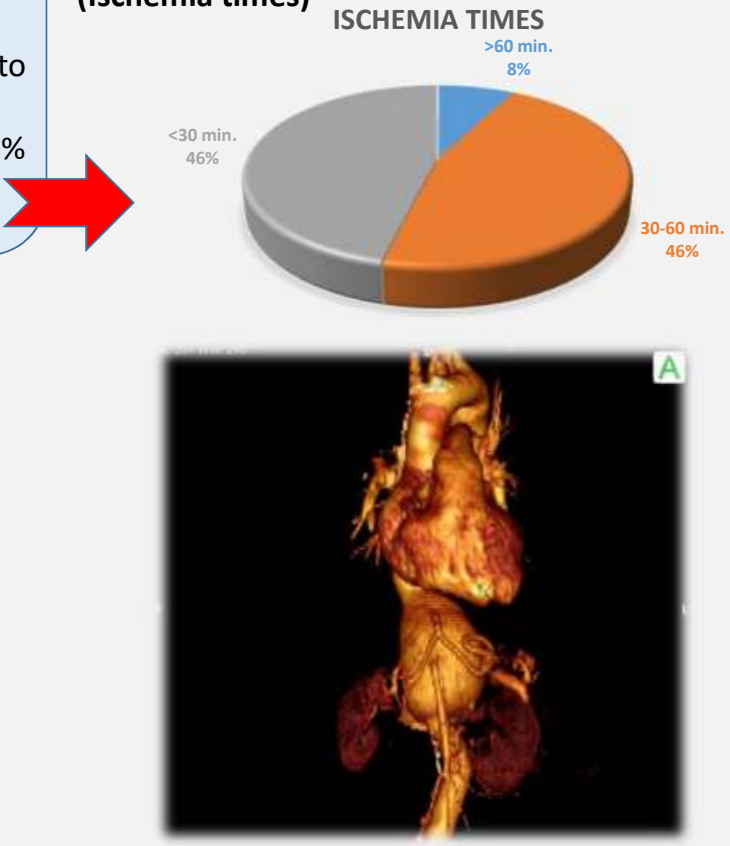

\section{CONCLUSIONS:}

In our experience, although It would be necessary to increase the sample size in order to establish a statistical significance, performing this surgery using ECMO seems to reduce perioperative complications due to the decrease in ischemia times. This could improve the patient prognosis. 